\title{
Artigo
}

\begin{abstract}
Resumo
Pretende-se, neste ensaio, uma reflexão acerca dos problemas concernentes ao final da análise com crianças e adolescentes. Através de um percurso bistórico abordando algumas das principais contribuições para a psicanálise infanto-juvenil, com destaque para as idéias de D. $W$. Winnicott, sugere-se que tanto o brincar, compartilhado com a crianca, quanto acompanhar, com humor, a luta do adolescente apontam na direção da "capacidade para estar só".

Descritores: clínica psicanalítica; final da análise; crianças; adolescentes; capacidade para estar só.
\end{abstract}

\section{SOBRE O FINAL DA ANÁLISE COM CRIANÇAS E ADOLESCENTES}

\author{
Daniel Kupermann
}

\begin{abstract}
"Quase parece como se a análise fosse a terceira daquelas profissões 'impossíveis' quanto às quais de antemão se pode estar seguro de chegar a resultados insatisfatórios.

As outras duas, conhecidas há muito mais tempo, são a educação e o governo".
\end{abstract}

(Freud, 1937/1980a, p. 282)

\section{Introdução}

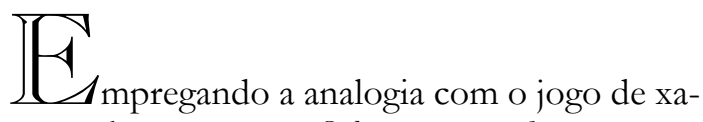
drez, Freud sugere, em Sobre o início do tratamento (1913/1980b), que somente a abertura e o final das partidas admitem uma apresentação sistemática e exaustiva, enquanto o desenrolar é marcado pela indeterminação; o mesmo ocorre com uma explanação, para os iniciantes, acerca do processo psicanalítico. Jacques Lacan (1968/2003, p.252), revendo essa passagem, sublinha que o começo e o fim do

Psicanalista, docente do Instituto de Psicologia da Universidade de São Paulo. 
"jogo" psicanalítico coincidiriam com a instalação e com os destinos da transferência, e que se pode constatar ser bem mais embaraçoso definir, como este finaliza. Foi em "Análise terminável e interminável", de 1937, que Freud se dedicou ao tema do final do tratamento psicanalítico. Trata-se de um ensaio escrito em seus últimos anos de vida, em grande parte como resposta à publicação, em 1928, de O problema do fim da análise por Sándor Ferenczi (1928/ 1992a), seu mais próximo interlocutor.

Pretendemos, neste ensaio, percorrer algumas das principais questões postas por Freud - que tem como matriz clínica sua experiência com adultos - acerca da finalização do processo analítico para, em seguida, delinear quais os problemas pertinentes ao final de análise com crianças e adolescentes. Em nenhum outro contexto a epígrafe citada acima - já gasta pelo excessivo uso que dela é feito pelos psicanalistas nas mais variadas situações - parece tão apropriada, considerando as imbricações que a análise com crianças tem com a educação, e aquelas que a análise de adolescentes tem com a política, além do fato de ambas as clínicas esbarrarem, recorrentemente, nos limites dos possíveis. De imediato pode-se sugerir que, se a definição do início do tratamento de crianças e adolescentes parece ser mais complexa que a de adultos, graças à participação decisiva da família no processo, refletir acerca do final desses tratamentos será ainda mais trabalhoso, obrigando-nos a delimitar os principais desafios, mais do que a oferecer respostas precisas e bem acabadas.

Os argumentos apresentados por Freud acerca da terminabilidade das análises detêm-se em quatro aspectos principais: o fator tempo; as condições para um final satisfatório da análise; o caráter profilático do tratamento; e os obstáculos à finalização do processo psicanalítico. Vamos a eles.

\section{Freud e o problema do final das análises}

\section{O fator tempo}

A primeira consideração freudiana acerca do fator tempo, ou seja, da duração do processo psicanalítico, é a de que o problema do fim das análises - referente à indagação acerca das condições adequadas para se avaliar o seu término - não deve ser confundido com a demanda da pressa (americana, diz-nos com franca ironia) para encurtá-las (Freud, 1937/1980a). Claro que a questão do tempo, no que se refere ao tratamento de crianças e adolescentes, tem suas especificidades. Caso contrário, a julgar pela duração habitual 
das análises atualmente, qualquer tratamento de criança ou adolescente irá se transformar, depois de uma ou duas décadas, em análise de adultos. Essa talvez seja a tendência com adolescentes, cuja fronteira com a definição de jovem adulto é tênue, mas não com crianças, que têm no período de latência - e no caso de o tratamento avançar através dela, na própria adolescência - marcos significativos para os quais estão previstas modificações técnicas importantes no processo analítico. Um aspecto decisivo para a temporalidade dos tratamentos de crianças e de adolescentes é, no entanto, a importância detida nessas análises pelos pais ou responsáveis, que podem pretender vê-las encurtadas por uma série de fatores.

\section{As condições para um final satisfatório da análise}

Do ponto de vista prático, Freud (1937/1980a) sublinha que o tratamento se encerrará quando os parceiros deixarem de se encontrar. Mas há duas condições para que se considere um término satisfatório do processo analítico. A primeira, que o analisando não esteja mais apresentando os sintomas em função dos quais buscou atendimento e que tenha superado a parcela restritiva das suas angústias e inibições; além disso, é preciso que o analista julgue que o grau de elaboração atingido justifique a não necessidade de temer uma repetição do mesmo processo que originou o sofrimento que trouxe o sujeito à análise. Se esses critérios não estiverem presentes, o processo é considerado interrompido, mas não finalizado. São critérios bastante razoáveis, mas convém considerar que é bastante freqüente, no caso de crianças e adolescentes, os tratamentos serem interrompidos antes que essas condições sejam atingidas, justamente pelo fato, já sublinhado, de que os responsáveis legais pela criança ou pelo adolescente podem decidir pela sua interrupção a qualquer momento.

\section{O caráter profilático do tratamento}

O fato de se esperar que as condições para um término satisfatório da análise sejam atingidas não é garantia de que um novo sofrimento psíquico não venha a acometer os analisandos, mas indício de que dificilmente haverá uma repetição dos mecanismos psíquicos já elaborados. O tratamento psicanalítico não é profilático, portanto, nada garante um equilíbrio permanente da economia psíquica do sujeito, e tampouco se pode prever, de antemão, as dificuldades e sofrimentos que o analisando terá que atravessar ao longo da vida. Apenas se pode oferecer, após um tratamento bem 
sucedido, um arranjo psicodinâmico mais adequado para que o sujeito possa enfrentar seu próprio destino.

O exemplo adotado por Freud para ilustrar os limites profiláticos da análise, apresentado no segundo capítulo de "Análise terminável e interminável" é, no entanto, polêmico: refere-se à análise empreendida por Freud com Ferenczi (como se sabe, apesar de a identidade do analisando não ter sido revelada na ocasião da publicação do ensaio). Freud faz alusão ao caso de um psicanalista (Ferenczi) muito bem sucedido profissionalmente e afetivamente que, anos após a sua análise, queixa-se de que seu analista (Freud) não havia analisado a sua transferência negativa. Seu argumento baseia-se no fato de que, na ocasião, não havia sinais de transferência negativa, e só se pode tratar do que está presentemente ativo. Por outro lado, "provocar" possíveis indícios de transferência negativa arriscaria comprometer a transferência positiva - principal aliada do tratamento, na sua concepção - e, portanto, a análise como um todo. A despeito de serem conhecidas as dificuldades de Freud no manejo dos afetos nas análises de seus discípulos, sobretudo no que concerne à transferência negativa, à hostilidade e à agressividade (Kupermann, 1996), esse episódio é ilustrativo dos obstáculos para se atingir um final de análise satisfatório; e ganha uma importância ainda maior no que se refere ao processo com crianças e, sobretudo, com adolescentes, como será desenvolvido adiante.

Em relação à clínica infanto-juvenil, entretanto, a preocupação de
Freud era menos a de alertar que a análise não é profilática, do que a de comprovar que, para as crianças, a análise não é iatrogênica, não iria "roubar sua inocência", como se encontra no "Pós-escrito" ao caso Hans (Freud, 1909/1980c), redigido em 1922. Na década de 1920, Hans já era um jovem homem e, como enfatiza Freud, saudável, apesar do divórcio dos pais e da complexidade de sua vida familiar, o que o deixara bastante isolado ${ }^{1}$. O único fato que intrigou Freud nessa ocasião foi que Hans declarou não se lembrar de nada do que se passou durante o período em que foi analisado (por Freud, através das interpretações veiculadas por seu próprio pai). A amnésia, típica da latência, ocorrera, apesar da análise. Freud aproxima, então, o processo analítico de um sonho, que nos acorda à noite, é analisado, mas esquecido pela manhã. Nesse ponto, convém perguntar: seria a amnésia um dos destinos privilegiados do final da análise com crianças que ainda não atravessaram o período da latência?

Um último aspecto referente ao caráter profilático de uma análise pode ser abordado retomando o episódio da queixa de Ferenczi de que Freud não lhe analisara os aspectos hostis da transferência - a transferência negativa. Pode-se perguntar se a reclamação de Ferenczi era mesmo injustificada, ou se remetia a um problema da maior importância para o desfecho satisfatório da análise: o da necessária disponibilidade sensível do psicanalista para que o tratamento chegue a bom termo. Mais explicitamente: a transferência negativa não 
estava mesmo presente, ou o analista não pôde suportá-la, evitando se oferecer como seu legítimo destinatário? Justamente essa questão ocupou parte importante da obra de Ferenczi em seus últimos anos de vida, levando-o a formular uma "segunda regra fundamental" para a psicanálise, junto à associação livre: a análise do analista (Ferenczi, 1928/1992b). Questão semelhante ocupou o pensamento, décadas depois, de Jacques Lacan (1968/2003), conduzindo ao conceito de "desejo do analista", e de Donald Winnicott (1975), sempre atento à necessidade de o analista poder se oferecer para ser usado pelos analisandos - sobretudo no que se refere ao papel de destinatário da sua agressividade.

\section{Os obstáculos à finalização do processo psicanalítico}

Ao se referir ao problema da cura em psicanálise, Freud (1937/ 1980a, p.252) sugere que é mais importante perguntar-se pelos obstáculos a ela do que se indagar sobre os seus critérios, suficientemente conhecidos. Claro que, nessa passagem, havia um cuidado na abordagem do problema da cura, para evitar seja a "pressa americana", já mencionada, seja a padronização de supostos critérios de normalidade que poderiam servir como seu indicador.

Quanto aos obstáculos à cura, Freud descreveu os graus de "alteração do ego" do analisando, a reação terapêutica negativa e a resistência à melhora; no entanto, no final do ensaio apresentou aquele que, desde então, é considerado o principal obs- táculo à análise, seu limite derradeiro: o "rochedo da castração", que se manifesta em ambos os sexos como repúdio à feminilidade (1937/ 1980a). Assim, na leitura de Freud, os obstáculos e os limites para uma análise estão, privilegiadamente, do lado do paciente.

Porém, no que se refere ao tratamento de crianças e adolescentes, os obstáculos seriam os mesmos? O intransponível rochedo da castração, ou o repúdio à feminilidade, também se imporia, nesses casos, como a principal barreira para o sucesso de um final de análise? Para responder a essas questões, encontramos três vertentes a serem investigadas. Em primeiro lugar, as dificuldades, por parte dos analistas, no manejo da transferência com crianças e adolescentes; além disso, as resistências à análise do lado dos pais; finalmente, escutar o que seria próprio ao tratamento da criança e do adolescente. Passemos à criança.

\section{Compartilhar com crianças}

"Raspem o adulto, e
encontrarão a criança"
(Ferenczi, 1909/1991)

O sentido imediato da máxima empregada por Ferenczi poderia ser interpretado de acordo com a avaliação freudiana do término do tratamento de Hans. Apesar de conceber que os sintomas fóbicos - tão freqüentes em crianças que atravessam o complexo de Édipo, devido à angústia de castração (Hans tinha 5 anos) - tendem a passar com o tempo, Freud considerou que os esclareci- 
mentos acerca das teorias sexuais infantis e as interpretações sugeridas para elucidar a formação dos sintomas haviam livrado Hans das inibições do recalque; inibições próprias das neuroses dos adultos. No pós-escrito ao caso, encontra-se a revelação de que não aprendera "nada de novo" com a análise de Hans (Freud, 1909/ 1980c, p.152). Ou seja, toda análise é, em última instância, análise do infantil; basta raspar o adulto, e mesmo a criança, e o que se encontra é sempre o infantil.

A prática clínica com crianças, porém, floresce apenas a partir dos anos 1920, graças à dedicação das psicanalistas que se dispuseram a ser as pioneiras da nova modalidade de atendimento e que, ao botarem a "mão na massa" - ao rasparem a criança - encontraram especificidades inegáveis, referentes ao emprego da regra fundamental da associação livre, ao estabelecimento do enquadre e ao manejo da transferência.

É recorrente, na história da psicanálise, a concepção de que os maiores obstáculos para a análise de crianças são justamente o emprego da associação livre e o estabelecimento de uma transferência dirigida ao analista (Arfouilloux, 1983). Quando iniciou os atendimentos infantis, ainda em 1921, von Hug Hellmuth visitava as crianças nas suas próprias casas, assimilava suas brincadeiras e jogos como material de análise, mas considerava que a transferência que a criança estabelece é do tipo "ideal”, como se o psicanalista ocupasse efetivamente o lugar de um dos pais, notadamente da mãe. Von Hug Hellmuth foi quem primeiro percebeu a importância efetiva da mãe no tratamento e, também, seu papel como obstáculo ao mesmo, sobretudo pelo "ciúme" e pela angústia de separação que a relação da criança com o analista pode suscitar.

Alguns anos depois, Anna Freud e Melanie Klein, em Viena e Berlim, respectivamente, desenvolveram enormemente a prática clínica com crianças. As "controvérsias" que tiveram lugar na Sociedade Britânica de Psicanálise (ambas emigraram para a Inglaterra) em torno das divergências entre as suas idéias repercutem até hoje, e muitos dos problemas aí suscitados continuam a instigar as pesquisas na comunidade psicanalítica (King \& Steiner, 1998).

Em O tratamento psicanalítico de crianças, Anna Freud (1971) afirma que as crianças não estabelecem uma neurose de transferência, uma vez que seus objetos primários de amor - os pais - ainda detêm papel crucial no seu processo de constituição subjetiva. Deixam, assim, de configurar "imagens", cujos contornos bem definidos poderiam ser reeditados na transferência analítica. Nesse sentido, os conteúdos dos jogos infantis não são considerados símbolos das relações com objetos internalizados, não caracterizando uma verdadeira associação livre; portanto, não deveriam ser interpreta- 
dos transferencialmente. Freud (1932/1980d) acompanhou os argumentos de Anna, acreditando que a análise com crianças esbarra nos limites da pedagogia, já que a criança persiste submetida à autoridade parental e, assim, não estabelece uma transferência legítima com o psicanalista. Essa posição contribui efetivamente para situar a clínica com crianças entre dois dos ofícios considerados impossíveis: o psicanalisar e o educar.

Por seu turno, Melanie Klein (1932/1997), criadora da "técnica de análise através do brincar", apostava que o primeiro dos obstáculos encontrados na clínica com crianças o emprego da associação livre - seria superado ao se considerar a brincadeira da criança a via régia para o inconsciente, do mesmo modo que o sonho o é na análise de adultos. $\mathrm{Na}$ concepção kleiniana, a brincadeira infantil é expressão autêntica das angústias e dos conflitos decorrentes da ambivalência e da culpa experimentada pela criança e, nesse sentido, pode e deve ser interpretada como qualquer formação do inconsciente. Em contrapartida, a inibição do brincar merece interpretações ainda mais precoces, sobretudo da transferência negativa, de maneira a arrefecer angústias e ameaças muito primitivas, possibilitando o estabelecimento de um enquadre adequado à análise. Para Klein, a transferência na clínica infantil é legítima, uma vez que os objetos, bem como o superego arcaico, são fantasiados precocemente pela criança.

Se Klein adotara como ponto de partida para a psicanálise com crian- ças o método psicanalítico tradicional - modificando-o, é claro, mas mantendo seus critérios de analisabilidade -, a questão imediata que se colocou para o campo psicanalítico foi a dos efeitos de retorno dessa experiência na concepção mais ampla do que é psicanalisar. Dessa maneira, encantado com o que assistia a partir das experiências de Anna Freud e, sobretudo, de Melanie Klein, Sándor Ferenczi adotou um estilo clínico inspirado na análise de crianças baseado na regressão à dependência e no jogo lúdico - também para a análise de adultos. Seu objetivo era buscar atingir a linguagem da ternura adequada para se comunicar com o infantil presente em cada analisando, como se encontra no ensaio Análises de crianças com adultos (Ferenczi, 1931/ 1992c). Com isso, a psicanálise com crianças mereceu uma dignidade até então inédita, passando efetivamente a influenciar o entendimento geral sobre a práxis psicanalítica.

O principal herdeiro do estilo clínico nomeado por Ferenczi "análise através do jogo" foi o pediatra e psicanalista britânico D. W. Winnicott. Coube a Winnicott (1975), que respirava uma atmosfera fortemente influenciada pelas idéias kleinianas, a denúncia segundo a qual os analistas ocupavam-se mais do conteúdo da brincadeira - de interpretá-la - do que do brincar como atividade autônoma de produção de sentido. E foi mérito seu o reconhecimento, pelo campo psicanalítico, da importância do brincar compartilhado com crianças.

Ao também botar a "mão na massa", tornando mais heterogênea a linhagem até então exclusivamente 
feminina dos analistas de crianças, Winnicott teve sucesso em tocar o ponto nevrálgico do processo de constituição da subjetividade. Antes do destacamento entre as experiências do mundo interno e do mundo externo, é preciso a vivência suficientemente boa da continuidade do ser. No entanto, sublinha Winnicott, "O centro de gravidade do ser não surge no indivíduo", mas na dupla amamentante. Ou seja, ao raspar a criança, Winnicott deparou-se não com qualquer núcleo irredutível que poderia ser considerado a sede do desejo ou a verdade do sujeito, o qual a análise deveria atingir regressivamente, mas com uma unidade definida pelo "contexto ambiente-indivíduo" (1952/2000, p.165).

Dessa unidade primordial, proporcionada pela figura da mãe suficientemente boa, emerge a experiência de ilusão e o sentimento de onipotência que permitirão à criança constituir uma região intermediária entre o seu self e a realidade que gradualmente a ela se apresenta. Nesse sentido, a subjetividade se engendra através de um espaço de experimentação - nomeado por Winnicott (1975) espaço potencial -, no qual o self inventa $\mathrm{o}$ mundo na medida em que o mundo convoca o self, em um processo criativo. Essas experiências ilusórias criadoras de si e do mundo compõem o campo dos fenômenos transicionais, do qual derivam as faculdades do fantasiar, do sonhar e do brincar.

A orientação winnicottiana para a clínica com crianças encontra-se, assim, com a kleiniana, no sentido de conceber que a principal tarefa de uma análise é fazer com que uma criança inibida em sua expressão lúdica possa brincar. E dela se afasta na medida em que concebe o tratamento como um processo no qual duas pessoas brincam juntas; para Winnicott (1975), o brincar compartilhado define não apenas a clínica com crianças, mas a psicanálise de forma geral.

De fato, essa idéia fora apresentada por Ferenczi nos momentos derradeiros da sua obra, quando a "neocatarse" e o jogo se impõem, no plano da clínica, para o sucesso dos processos de elaboração (Ferenczi, 1930/1992d, 1931/1992c). Mas é no Diário clínico (1932/1990, p.91) que nos deparamos com a sua formulação mais decisiva e, também, mais embaraçosa: a de que em certos momentos da análise a impressão que se tem é a de duas crianças que trocam suas experiências, amparam-se mutuamente e, configurando uma "comunidade de destino", podem também brincar juntas.

A concepção de que uma análise - qualquer análise, de adultos bem como de crianças - pressupõe o encontro de "duas crianças" - o analisando e o analista - aparece também em Winnicott, para quem a terapêutica efetua-se na "superposição de duas áreas lúdicas, a do paciente e a do terapeuta". Entretanto, a conseqüência dessas formulações é a exigência de uma implicação com o sofrimento do analisando e de uma especial sensibilidade afetiva por parte do psicanalista que, se não puder brincar, simplesmente "não se adéqua ao trabalho" (Winnicott, 1975, p.80). Afinal, ser afetado pelo impacto trau- 
mático e pela intensidade lúdica da criança requer uma grande disponibilidade psíquica, o que torna a prática clínica com crianças, na maioria dos casos, mais difícil e mais delicada do que a psicanálise com adultos (Dolto, 1985).

No que se refere ao final de análise, apesar de Anna Freud e Melanie Klein não terem se dedicado à reflexão acerca da sua especificidade com crianças, um aspecto privilegiado por ambas é a relação estabelecida pelas crianças, após o processo analítico, com seu ambiente imediato, ou seja, com os pais. Nesse sentido, malgrado suas divergências, tanto Anna Freud quanto Klein ressaltaram a importância do acolhimento e do manejo dos conflitos, angústias, expectativas e culpabilidades dos pais - sobretudo das mães. Em uma nota de rodapé de A psicanálise de crianças, Klein (1932/1997, p.32) indica que, ao término do tratamento, deve-se esperar, além do resgate da possibilidade de brincar e elaborar situações traumáticas, que a criança possa restabelecer uma boa convivência com seu ambiente e com seus pais².

Apesar de ter se dedicado à análise de adultos, Jacques Lacan (2003) circunscreveu com bastante precisão essa problemática, ao postular - na sua contribuição à psicanalista Jenny Aubry - que a sintomatologia da criança está referida ao lugar que ocupa na família, privilegiadamente no fantasma materno. Sua primeira hipótese, de prognóstico mais favorável, é a de que o sintoma da criança expressa a "verdade" do casal parental. Trata-se sempre de uma situação complexa, já que implica a constituição desejante de cada um dos pais, e de difícil abordagem clínica, uma vez que a escuta dos pais se impõe como condição sine qua non do tratamento, considerando os riscos de boicote e interrupção aí implicados. A alternativa, de prognóstico mais sombrio e mais próximo da instalação de uma psicose, é a de que a criança ocupa um lugar irredutível no fantasma materno, podendo-se dizer, nesse caso, que a criança se torna o "objeto" da mãe, sem outra função que não a de "revelar a verdade desse objeto" (2003, p.369).

A escola francesa de psicanálise com crianças, que tem Françoise Dolto e Maud Mannoni como principais expoentes, adotou como ponto de partida a orientação lacaniana, manifestando a tendência a escutar o sintoma da criança como efeito da constituição do laço parental, privilegiadamente do desejo da mãe. Essa concepção parece sugerir uma passividade radical da criança frente ao desejo do Outro, representado pela família em que se encontra inserida. Algumas críticas se fizeram nesse sentido (Poulain-Colombier, 1986; Zornig, 2000) e, no limite, poder-se-ia de fato perguntar humoristicamente, como o faz Maria Cristina Kupfer (2002): "pais, melhor não tê-los?". 
No entanto, para além das caricaturas, a questão crucial que se coloca é a do que se pode esperar do final de uma análise de criança, considerando sua efetiva dependência do desejo materno e do ambiente familiar. A abordagem dessa questão remete-nos de volta ao texto freudiano, no qual o rochedo da castração impõe-se como obstáculo derradeiro para um término satisfatório do tratamento.

Reconhecendo que a clínica com crianças tem especificidades; que o tratamento psicanalítico na infância não se confunde com a análise do infantil, presente tanto nas crianças quanto nos adultos; e, sobretudo, considerando o lugar da criança frente ao fantasma materno, pode-se conceber, acompanhando Silvia Zornig (1999), que a questão do fim da análise com crianças remete ao confronto com a castração materna e à possibilidade de a criança não responder, com o seu próprio corpo, ao gozo materno. O desafio imposto para a criança no percurso da sua análise é, assim, o de constituir seu próprio fantasma e, não menos importante, seu plano singular de criação. Essa operação exige, decerto, uma temporalidade específica, como é sugerido pela amnésia de Hans. Afinal, um término satisfatório de análise de criança só pode, efetivamente, ser avaliado a posteriori, com as vicissitudes da adolescência.

Assim, se a questão do final de análise com crianças remete ao período de latência e à amnésia que só ganhará novo sentido na adolescência, passemos à reflexão acerca do final do tratamento com adolescentes.

\section{Acompanhar adolescentes}

"Não sabemos o que queremos, mas sabemos o que não queremos" (muros de Paris, maio de 1968)

"O jovem de hoje sente que a psicanálise está nas mãos da geração dos seus pais e é, assim, suspeita"

(Anna Freud, 1968/1974)

Em alguns ensaios da década de 1960 - marcada pelas rebeliões juvenis em todo o mundo - e de 1970, Winnicott indicou com precisão o paradoxo vivido pelo adolescente: a "necessidade" de poder rebelar-se em um contexto ambiental que acolha, contenha e detenha essa mesma rebelião (Winnicott, 1961/2005, 1964/ 2002, 1975).

Octave Mannoni, em um artigo bastante esclarecedor intitulado A adolescência é analisável? (1996), sublinha a importância das idéias de Winnicott para a clínica com adolescentes, e auxilia-nos a 
organizar essas mesmas idéias, apresentadas de modo nem sempre sistemático. A chamada "crise" da adolescência foi concebida pelo psicanalista inglês como sinal de saúde, não devendo ser tratada ou analisada, mas "acompanhada" e confrontada. Assim, tanto a sociedade de um modo geral quanto o psicanalista no setting clínico deveriam se dispor a acompanhá-la ativamente para que pudesse ganhar consistência afetiva na experiência do adolescente e, dessa maneira, possibilitar alguma elaboração. Mannoni sugere, além disso, que as patologias que afligem os adolescentes são "crises" impedidas de se manifestar e de ganhar expressão.

Etimologicamente, Krisis indica estado agudo, mas também momento de julgamento e de decisão; no caso da medicina, julgamento e decisão entre a vida e a morte. Segundo Winnicott (1961/2005, 1964/2002, 1975), a crise da adolescência tem um tempo de duração, e demanda que a sua temporalidade seja acolhida pelo ambiente. Os distúrbios que acometem gravemente adolescentes - depressão, esquizofrenia e paranóia, compulsões, bem como o risco de suicídio - podem indicar efetivamente um não vivido, seja pela falta de sustentação dos pais, seja pela intolerância do meio social.

A crise de adolescência é marcada, sobretudo, pela "problemática identificatória" (Mannoni, 1996). O adolescente encontra-se frente a duas tarefas que exigem um enorme trabalho psíquico: desligar-se dos primeiros objetos de amor infantil - pai e mãe - para poder constituir novos objetos de investimento libidinal e posicionar-se como adulto em uma cultura que, no entanto, impõe-lhe uma "moratória" (Erikson, 1976) que tende a ser tanto decepcionante quanto agonizante. Nesse sentido, Winnicott (1975) insiste em que a "luta" do adolescente caracteriza-se pela agressividade e pela necessidade de "assassinar" os pais, suportando a angústia do desamparo e a culpa por essas mortes e assassinatos. A desidealização e a desidentificação por que passa o adolescente remetem à necessidade de um trabalho de luto, condição para a criação de novos objetos de satisfação erótica e para a sublimação, que possibilitará o ingresso no universo dos adultos e o desfrute das satisfações e realizações há muito prometidas.

Pode-se considerar, acompanhando os problemas anteriormente expostos, que a contribuição mais original de Winnicott para o vislumbre de um término satisfatório na clínica de adolescentes está na noção de uso do objeto (Winnicott, 1975). De fato, na concepção winnicottiana da transferência, o psicanalista, além de representar imagos com as quais o analisando se relaciona de modo conflituoso, deve também poder se oferecer para ser efetivamente usado. Para o analisando, o uso do analista implica destruir seus objetos subjetivos para encontrar um novo objeto, do qual o psicanalista é o suporte, não mais como feixe de projeções fantasmáticas, porém como alteridade radical, a parte diferente-de-si que habita o sujeito (p.131). A condição necessária para essa operação crucial é a de que o psicanalista sobreviva a sua destruição; o que pressupõe, além 
da sua presença sensível, que não haja retaliação da agressão sofrida; deixarse morrer, para renascer em outro espaço e tempo.

Assim, resgatando a analogia freudiana com o jogo de xadrez, percebe-se que a clínica com adolescentes impõe ao psicanalista o enfrentamento de desafios radicais tanto em seu lance de abertura quanto no do fechamento. De início, trata-se de decidir se há sofrimento e dor legítimos para serem acompanhados, ou se a demanda dos pais e da sociedade pelo tratamento do adolescente revela a sua própria dificuldade em acolher positivamente os movimentos agressivos e em conter com dignidade a luta do adolescente. Quanto ao final, este implica a disponibilidade sensível do psicanalista para se oferecer como destinatário adequado para a agressividade criadora e, também, para a transferência negativa, cujo manejo sempre provocou dificuldades ao longo da história da psicanálise.

A noção de luta, através da qual Winnicott nomeia a crise de adolescência, explicita, portanto, a dimensão de embate político embutido na problemática do adolescente - o que faz da clínica do adolescente o locus privilegiado onde se cruzam, de modo mais decisivo, as três profissões nomeadas por Freud impossíveis (psicanálise, educação e governo). Além disso, permite relativizar as dificuldades encontradas no tratamento dos adolescentes, o que foi intuído - mas não suficientemente elaborado - por Anna Freud (1968/ 1974), justamente em 1968, ano em que as revoltas juvenis inflamaram o
Ocidente; isto é, talvez essas dificuldades residam não tanto no caráter supostamente intratável do sofrimento adolescente, mas sobretudo na incompreensão dos próprios psicanalistas com respeito à questão imposta socialmente pela adolescência.

Contudo, mesmo entendendose que há uma efetiva demanda de tratamento por parte do adolescente, persiste o impasse delineado por Winnicott (1961/2005): analisar quem não quer ser "compreendido". O psicanalista precisaria contar, nesse caso, com o despojamento que lhe permite evitar colocar-se no lugar de detentor do saber, para "jogar" com seu analisando adolescente. Como escreve Mannoni: "não é opondo o imaginário ao simbólico que se vai curar... o imaginário em nome da verdade... $\mathrm{O}$ analista não ganha nada se permanecer do lado do saber" (1996, p.34).

No entanto, o que significa jogar/brincar ${ }^{3}$ com o adolescente? Vimos de que maneira a brincadeira se impôs no setting psicanalítico a partir das contribuições de Ferenczi e de Winnicott, caracterizando um novo estilo de psicanalisar, no qual importa menos a interpretação desveladora do conteúdo inconsciente dos jogos, do que a circulação dos afetos promovida pelo brincar. Seguindo essa pista, uma sugestão para a clínica com adolescentes seria dispor do humor - a "brincadeira do adulto" (Freud, 1908/1980e) - compartilhado entre analista e analisando. Ao rir de si mesmo, o psicanalista facilita o trabalho de desidealização e de desidentificação ao qual o adolescente se dedica em seu longo e penoso tra- 
balho de luto. É mesmo notório o cultivo do humor ao qual os adolescentes se dedicam nas suas modalidades de laço social. Ao mesmo tempo, a circulação do humor entre analista e analisando poderia contribuir para um escape das fobias, do pânico, e das "falsas soluções" paranóicas para a angústia do desamparo, marcadamente as da adesão a projetos fundamentalistas de existência e as da violência dos grupos delinqüentes, bastante freqüentes no contemporâneo (Winnicott, 1964/2002).

A atitude humorística é, como já suficientemente demonstrado (Kupermann, 2003, 2005), avessa a toda e qualquer idealização superegóica, e remete ao inevitável estado de orfandade a que nos vemos submetidos desde o advento da modernidade, sem lenço, sem documento, mas com a possibilidade de viver de modo criativo. Uma condição decisiva, no entanto, para se poder rir de si mesmo quando se está sendo permanentemente atacado em sua posição de saber/poder, como no caso da clínica com adolescentes é, como alerta Winnicott (1964/ 2002), evitar a inveja que o adolescente nos provoca. Isso implica que o analista tenha sucesso ao se remeter a sua história de vida, a sua loucura, ao sofrimento e à liberdade, experimentados na própria adolescência.

O que parece, enfim, haver de comum no final das análises de crianças e de adolescentes é a aquisição, pelos analisandos, do que Winnicott (1958/1990) nomeou "capacidade para estar só". Seja para conquistar alguma autonomia em relação à verdade do casal parental e ao fantasma da mãe, no caso da criança; seja para percorrer a penosa travessia rumo à independência, no caso do adolescente.

Compartilhar com a criança e acompanhar o adolescente é, assim, dispor-se a uma comunicação direta com seu silêncio e sua solidão, estabelecendo uma ressonância afetiva que lhes permite ficar sós, mas não traumaticamente abandonados.

\begin{abstract}
This essay intends to lead to reflection on the problems concerning the end of analysis with children and adolescents. By taking a bistorical path through some of the most important contributions to infanto-juvenile clinical practice, especially the ideas of $D . W$. Winnicott, we suggest that playing together with the child, as well as accompany, with humour, the fight of the adolescent, lead to the "capacity to be alone".
\end{abstract}

Index terms: psychoanalytical clinic; end of analysis; children; adolescents; capacity to be alone.

194 Estilos da Clínica, 2007, Vol. XII, n²3, 182-197 


\section{Artigo}

\section{Resumen}

En este ensayo, se pretende reflexionar sobre los problemas vinculados al final del análisis con niños y adolescentes. A partir de trazar la trayectoria bistórica de las principales contribuciones para el psicoanálisis de la infancia y la adolescencia, con especial destaque para las ideas de D.W.Winnicott, se sugiere que tanto el juego compartido con el niño, cuanto acompañar, con humor, la lucha del adolescente, apuntan en la dirección de la "capacidad para estar solo".

Palabras clave: clínica psicoanalítica; final del análisis; niños; adolescentes; capacidad para estar solo.

\section{REFERÊNCIAS BIBLIOGRÁFICAS}

Arfouilloux, J.-C. (1983). Entrevista com a criança: A abordagem da criança através do diálogo, do brinquedo e do desenho (A. Ribeiro, trad.). Rio de Janeiro: Zahar.

Erikson, E. (1976). Identidade, juventude e crise (A. Cabral, trad.). Rio de Janeiro: Zahar.

Dolto, F. (1985). Seminário de psicanálise de crianças (Vera Ribeiro, trad.). Rio de Janeiro: Zahar.

Ferenczi, S. (1990). Diário clínico (A. Cabral, trad.). São Paulo: Martins Fontes. (Trabalho original escrito em 1932).

(1991). Transferência e introjeção. In S. Ferenczi, Psicanálise I (A.

Cabral, trad., pp. 77-108). São Paulo: Martins Fontes. (Trabalho original escrito em 1909).

(1992a). O problema do fim da análise. In S. Ferenczi, Psicanálise IV (A.

Cabral, trad., pp. 15-24). São Paulo: Martins Fontes. (Trabalho original escrito em 1928).

(1992b). Elasticidade da técnica. In S. Ferenczi, Psicanálise IV (A. Cabral, trad., pp. 25-36). São Paulo: Martins Fontes. (Trabalho original escrito em 1928).

(1992c). Análises de crianças com adultos. In S. Ferenczi, Psicanálise IV (A. Cabral, trad., pp. 69-83). São Paulo: Martins Fontes. (Trabalho original escrito em 1931).

(1992d). Princípio de relaxamento e neocatarse. In S. Ferenczi, Psicanálise IV (A. Cabral, trad., pp. 53-68). São Paulo: Martins Fontes. (Trabalho original escrito em 1930).

Freud, A. (1971). O tratamento psicanalítico de crianças (M. A. Moura Matos, trad.). Rio de Janeiro: Imago. (Trabalho original escrito em 1926).

(1974). Difficultés survenant sur le chemin de la psychanalyse. Nouvelle revue de psychanalyse, 10, Paris: Gallimard. (Trabalho original escrito em 1968).

Freud, S. (1980a. Análise terminável e interminável. In S. Freud, Edição standard brasileira das obras psicológicas completas de Sigmund Freud (J. Salomão, trad., Vol. 23, pp. 239-288). Rio de Janeiro: Imago. (Trabalho original publicado em 1937). 
(1980b). Sobre o início do tratamento. In S. Freud, Edição standard brasileira das obras psicológicas completas de Sigmund Freud (J. Salomão, trad., Vol. 12, pp. 164-192). Rio de Janeiro: Imago. (Trabalho original publicado em 1913).

(1980c). Análise de uma fobia em um menino de cinco anos. In S. Freud, Edição standard brasileira das obras psicológicas completas de Sigmund Freud (J. Salomão, trad., Vol. 10, pp. 15-158). Rio de Janeiro: Imago. (Trabalho original publicado em 1909).

(1980d). Novas conferências introdutórias sobre a psicanálise - conferência XXXIV. In S. Freud, Edição standard brasileira das obras psicológicas completas de Sigmund Freud (J. Salomão, trad., Vol. 22, pp. 167-192). Rio de Janeiro: Imago. (Trabalho original publicado em 1932).

(1980e). Escritores criativos e devaneio. In S. Freud, Edição standard brasileira das obras psicológicas completas de Sigmund Freud (J. Salomão, trad., Vol. 9, pp. 149-162). Rio de Janeiro: Imago. (Trabalho original publicado em 1908).

King, P \& Steiner, R. (Orgs.). (1998). As controvérsias Freud-Klein 1941-45. (A. M. Spira, trad.). Rio de Janeiro: Imago.

Klein, M. (1991). Sobre os critérios para o término de uma psicanálise. In M. Klein, Obras Completas de Melanie Klein. Vol. III. Inveja e gratidão e outros trabalhos 1946-1963 (B. H. Mandelbaum et alii, trad., pp. 6469). Rio de Janeiro: Imago. (Trabalho original publicado em 1950).

Klein, M. (1997). A psicanálise de crianças (Liana P. Chaves, trad.). Rio de Janeiro: Imago. (Trabalho original publicado em 1932)

Kupermann, D. (1996). Transferências cruzadas. Uma história da psicanálise e suas instituições. Rio de Janeiro: Revan.

(2003). Ousar rir. Humor, criação e psicanálise. Rio de Janeiro: Civilização Brasileira.
(2005). Perder a vida, mas não a piada. O humor entre companheiros de descrença. In A. Slavutsky \& D. Kupermann (Orgs.), Seria trágico... se não fosse cômico. Humor e psicanálise (pp. 21-49). Rio de Janeiro: Civilização Brasileira.

Kupfer, M. C. (2002). Pais: melhor não têlos? In A. M. S. de Rosenberg (Org.), O lugar dos pais na psicanálise de crianças (pp. 99-119). São Paulo: Escuta.

Lacan, J. (2003). Proposição de 9 de outubro de 1967. In J. Lacan, Outros escritos (Vera Ribeiro, trad., pp. 248-264). Rio de Janeiro: Jorge Zahar. (Trabalho original publicado em 1968).

(2003). Nota sobre a criança.

In J. Lacan, Outros escritos (Vera Ribeiro, trad., pp. 369-370). Rio de Janeiro: Jorge Zahar. (Trabalho original escrito em 1969).

Mannoni, O. (1996). A adolescência é analisável? (Telma Queiroz, trad.) In A. I. Corrêa (Org.) Mais tarde é agora! Ensaios sobre a adolescência. Salvador: Agalma.

Poulain-Colombier, J. (1986). Historique des concepts et des techniques. Littoral, 18, Paris: Erès.

Winnicott, D. W. (1975). O brincar e a realidade. (J. Abreu e V. Nobre, trad.). Rio de Janeiro: Imago (Trabalho original publicado em 1971).

(1990). A capacidade para estar só. In D. W. Winnicott, $O$ ambiente e os processos de maturação (Irineo Ortiz, trad., pp. 31-37). Porto Alegre, RS: Artes médicas. (trabalho original publicado em 1958).

(2000). Ansiedade associada à insegurança. In D. W. Winnicott, Da pediatria à psicanálise. Obras escolbidas (Davy Bogomoletz, trad.,163-167). Rio de Janeiro: Imago. (Trabalho original publicado em 1952).

(2002). A juventude não dormirá. In Privação e delinqüência (A. Cabral, trad., pp. 177-182). São Paulo: Martins 


\section{Artigo}

Fontes, (Trabalho original publicado em 1964).

(2005). Adolescência, transpondo a zona das calmarias. In $A$ família e o desenvolvimento individual (M. B. Cipolla, trad., pp. 115-128). São Paulo: Martins Fontes. (Trabalho original publicado em 1961).

Zornig, S. (1999). A questão do desamparo na clínica psicanalítica com crianças. Pulsional - Revista de Psicanálise, (12) 126, 63-69.

(2000). A criança e o infantil em psicanálise. São Paulo: Escuta.

\section{NOTAS}

1 A questão do isolamento na clínica de adolescentes e sua diferença para com a capacidade para ficar só será examinada na última parte deste ensaio.

${ }^{2}$ Ver também Sobre os critérios para o término de uma psicanálise (Klein, 1950/1991).

3 No alemão (spielen), no inglês (to play) e no francês (jourr), uma única palavra é utilizada para os sentidos que atribuímos a jogar e brincar. Entre nós no Brasil, jogo está mais referido a atividades lúdicas e esportivas adultas, enquanto o brincar é reservado principalmente às atividades infantis.

danielk@openlink.com.br

Recebido em agosto/ 2007. Aceito em novembro/2007. 